\title{
Temporal Interactions in the Cat Visual System. III. Pharmacological Studies of Cortical Suppression Suggest a Presynaptic Mechanism
}

\author{
Sacha B. Nelson \\ Robert Bosch Vision Research Center, The Salk Institute for Biological Studies, San Diego, California 92138, and \\ Department of Biology, University of California at San Diego, La Jolla, California 92093
}

\begin{abstract}
When tested with pairs of brief visual stimuli, neurons of the primary visual cortex of the cat show a long-lasting, orientation-selective suppression, termed "paired-pulse suppression." The hypothesis that this suppression is due to GABA $_{A}$-mediated inhibition was tested by performing temporal interaction tests before, during, and after iontophoretic application of the selective antagonist bicuculline methiodide (BMI). In keeping with previous reports, BMI elevated the spontaneous and evoked firing rates of cortical neurons, and altered basic receptive field properties. Under the influence of BMI, most neurons showed a reduced or abolished selectivity for stimulus orientation and direction of movement. The effects on orientation selectivity required higher ejection currents than did the effects on directional selectivity. At high ejection currents, most cells did lose selectivity for the orientation of a moving stimulus, but retained some selectivity for the orientation of a stationary stimulus. BMI, even at very high ejection currents, did not abolish pairedpulse suppression. In some cells, BMi enhanced or prolonged paired-pulse suppression. In further experiments, temporal interaction tests were performed in which one or the other of the component stimuli was replaced with a pharmacological stimulus (a pulse of glutamate or potassium). A pharmacological stimulus did not produce suppression of the response to a subsequent visual stimulus, nor did a visual stimulus suppress the response to a subsequent pharmacological stimulus. Paired-pulse suppression occurred only when both stimuli were visual. Taken together with previous results, the present data indicate that paired-pulse suppression is most likely due to a presynaptic mechanism.
\end{abstract}

The apparent orientation of a visual contour is influenced by the presence of other contours at neighboring locations or at the same location but preceding it in time. In particular, when 2 similar but not identical orientations are viewed, either simultaneously or consecutively, the apparent angular separation between them is increased. This enhancement of orientation contrast is common to a number of visual illusions, such as the tilt illusion and aftereffect and the geometric illusions of Hering, Zöllner, Poggendorf, and others. Several authors have suggested

\footnotetext{
Received July 5, 1989; revised Aug. 3, 1990; accepted Aug. 30, 1990.

I am grateful to Dr. Simon LeVay for support and advice, to Tom Albright for helpful discussions, and to Thomas Voght for help with electrode construction. This work was supported by NIH Grant EY05551 to Simon LeVay and by Medical Scientist Training Grant PHSGM07198.

Correspondence should be addressed to Sacha Nelson, The Salk Institute for Biological Studies, P.O. Box 85800, San Diego, CA 92138.

Copyright (C) 1991 Society for Neuroscience $0270-6474 / 91 / 110369-12 \$ 03.00 / 0$
}

that the mechanism underlying these phenomena is lateral inhibition between visual cortical neurons subserving similar orientations (Blakemore et al., 1970; Carpenter and Blakemore, 1973; Nelson, 1985). In most of these reports, it is assumed that the function of this inhibition is to sharpen orientation tuning. In an accompanying paper, it was shown that neurons in the primary visual cortex of the cat show an orientation-selective suppression (referred to as "paired-pulse suppression"), which is similar in time course and in orientation and spatial tuning to the proposed lateral inhibition (Nelson, 1991a). In the present study, pharmacological techniques were employed in an attempt to learn more about the mechanism underlying the suppression. In particular, the hypothesis that it results from a postsynaptic inhibitory process was tested by applying bicuculline methiodide (BMI), which selectively and reversibly blocks the activation of cortical $\mathrm{GABA}_{\mathrm{A}}$ receptors (Curtis and Felix, 1971; Sillito, 1975a).

Previous studies have demonstrated that the blockade of bicuculline-sensitive GABA receptors impairs or abolishes the orientation selectivity of most of the neurons in the primary visual cortex (Daniels and Pettigrew, 1973, 1975; Blakemore and Rose, 1974; Sillito, 1975b, 1979; Tsumoto et al., 1979; Sillito et al., 1980b). However, the effects of bicuculline (or BMI) are not limited to orientation selectivity. It has also been reported to alter end-stopping (Daniels and Pettigrew, 1975), ocular dominance (Sillito et al., 1980), direction selectivity (Sillito, 1977), and the spatial organization of on and off responses (Sillito, 1975b). In most of these studies, the changes in receptive field properties were accompanied by an increase in the spontaneous and evoked discharge. Although the major focus of the present study was the effect of BMI on paired-pulse suppression, the effects of BMI on orientation and direction selectivity and on the magnitude of spontaneous and evoked activity were also monitored. This served 2 functions: First, it helped to confirm that BMI was being effectively applied. Second, it offered a chance to test the hypothesis that paired-pulse suppression is caused by a lateral inhibitory mechanism whose function is to sharpen orientation tuning. If this hypothesis were correct, a given dose of BMI applied to a particular neuron should broaden the orientation tuning and block paired-pulse suppression to a similar degree. The results suggest that this hypothesis is not correct. BMI does not block paired-pulse suppression in most neurons and, in some neurons, actually enhances it. BMI does, however, as previously reported, broaden cortical orientation selectivity.

A second test of the hypothesis that paired-pulse suppression is due to postsynaptic inhibition was performed by substituting an excitatory pharmacological stimulus (a pulse of glutamate or 
potassium) for the visual test stimulus used to measure pairedpulse suppression. The reasoning behind this experiment was that, if paired-pulse were accompanied by a hyperpolarization of the cell membrane, this should equally affect the response to iontophoretic and visual stimuli. If, on the other hand, the suppression is presynaptic in origin, the response to the iontophoretic stimulus should be unaffected. This was, in fact, observed. Although this experiment cannot rule out the possibility of postsynaptic inhibition that is electrotonically remote from the cell soma, the most straightforward interpretation is that the suppression is presynaptic in origin.

\section{Materials and Methods}

Extracellular recordings were obtained from 8 paralyzed, anesthetized adult cats. Details of the anesthesia, surgical preparation, visual stimulation, and data analysis are described in an accompanying paper (Nelson, 1991a) and therefore are described here in abbreviated form. Surgical preparation was performed under ketamine anesthesia supplemented with barbiturate. Recording was performed under barbiturate anesthesia. Animals were paralyzed with gallamine triethiodide and artificially respirated. Nictitating membranes were retracted with Neo-Synephrine and accommodation was paralyzed with atropine. Plastic contact lenses of appropriate curvature were used to prevent drying and to focus the eyes on the stimulus display monitor $57 \mathrm{~cm}$ away.

\section{Recording and iontophoresis}

Micropipettes were pulled on a Kopf 700D puller from 3-barreled glass blanks (World Precision Instruments [WPI]). Tips were broken back to a total diameter of 5-7 $\mu \mathrm{m}$, which meant that the tip of each barrel had an inner diameter of 1-2 $\mu \mathrm{m}$. In all experiments, 2 barrels were filled with drugs. In 3 experiments, recordings were made through the third barrel, which was filled with $1.5 \mathrm{M} \mathrm{Na}^{+}$acetate. In the remaining experiments, a separate lacquer-insulated tungsten electrode (Haer) was attached to the micropipette with cyanoacrylate. By bending the tip of the micropipette at the time of pulling, the tips of the recording electrode and micropipette were brought to between 30 and $100 \mu \mathrm{m}$ of each other. The following solutions were used: $0.5 \mathrm{M}$ GABA (Sigma; pH, 3.5), 0.2 M glutamate (Sigma; pH, 8.0), $0.01 \mathrm{~m}$ bicuculline methiodide (Sigma) in $0.165 \mathrm{M} \mathrm{NaCl}$ at $\mathrm{pH} 3.5$, and $1.5 \mathrm{M} \mathrm{KCl}(\mathrm{pH}, 7.4)$. Fresh solutions were preparcd for each experiment.

Iontophoretic current was supplied by a constant current source (WPI microiontophoretic current programmer 260) under manual or computer control. For the ejection of drugs, a 10-15-nA backing current was switched off, and an ejection current of the appropriate polarity (positive for $\mathrm{GABA}, \mathrm{BMI}$, or $\mathrm{KCl}$; negative for glutamate) was switched on. No balancing currents were used.

\section{Visual stimulation}

Upon isolating a single unit, its receptive field was mapped by hand using projected bars and spots of light. Cells were classified as simple or complex based on the presence or absence of spatially discrete on and off responses to hand-held stimuli. Quantitative testing was performed using a computer-controlled Picasso image synthesizer (for details, see Nelson, 1991a). The orientation and direction selectivity of each cell were tested concurrently by measuring the response to moving bars presented at each of 12 directions, spaced $30^{\circ}$ apart. The size and speed of the bars were adjusted to be optimal for each cell studied. Each trial was repeated 5-20 times in a randomly interleaved fashion. Temporal interactions were measured using stationary bars of optimal size and orientation presented at the most responsive region within the receptive field. Each trial consisted of a 200 -msec test stimulus presented either alone (control condition) or following a 200 -msec condition stimulus. Most cells were tested at condition-test interstimulus intervals (ISIs) of 200, 400, and 600 msec. Each trial was repeated 20 times. For some cells, the orientation tuning of the paired-pulse suppression was studied by varying the orientation of the condition stimulus while continuing to present the test stimulus at the cell's preferred orientation.

\section{Response analysis}

The response measure used both in orientation/direction and in temporal interaction tests was the firing rate during the most responsive 100 -msec period minus the spontaneous activity. The degree of direc- tional selectivity exhibited by a cell was assessed by calculating a directionality index (DI). This index was the ratio of the response in the null direction to that in the preferred direction. A value of 1.0 indicated a lack of directional tuning, and a value of 0 indicated a complete suppression of the response in the null direction. For a given cell, the preferred direction was defined with respect to the responses obtained in the absence of applied drugs. Thus, indices calculated from responses obtained under the influence of BMI were occasionally greater than 1.0, indicating a reversal of the preferred direction. Orientation selectivity was assessed by calculating the half-width at half-height of the oricntation tuning curve. When moving stimuli were used, the maximum half-width was $180^{\circ}$. When stationary stimuli were used, the maximum half-width was $90^{\circ}$. Tuning curves that had an apparent half-width of greater than the maximum (i.e., for which the response never fell below half-maximal) were considered to be unoriented. Temporal interactions were evaluated by calculating a temporal interaction index, defined as the ratio of the response to the test stimulus, when preceded by a condition stimulus, to that obtained when the test stimulus was presented alone.

\section{Procedure}

Iontophoretic blockade of inhibition. After measuring the orientation and direction selectivity and the degree of paired-pulse suppression for a given cell, BMI was applied iontophoretically. In a little over half of the cells studied, the initial BMI dose was calibrated using the procedures outlined by Sillito (1975a). A dose of GABA that completely suppressed spontaneous and evoked activity was first applied (4-20 nA), then the BMI current was increased until the effect of the applied GABA was completely blocked. At this dose of BMI (usually 15-20 nA), modest increases in the GABA current usually had no effect. The visual tests described above were then repeated while the BMI application was maintained. The BMI current was then discontinued, and the cell was allowed to recover $(5-45 \mathrm{~min}$ ) before the tests were repeated. In almost all cells, the effects of BMI were fully reversible. In most cells, the tests were then repeated, this time with a BMI current that was 2-5 times the initial dose. This dose was reduced when necessary to prevent the epileptiform bursting that was sometimes observed with high currents applied for long ejection periods. For some cells, the high dose of BMI was begun immediately following the low dose, without the intervening recovery period. The tests were then repeated a final time after another recovery period. In many cells, the entire sequence was repeated. For the cells that were not studied with GABA, the BMI dose was adjusted to produce maximal changes in spontancous and evoked activity without producing epileptiform bursting. For the purposes of comparison, the dose of BMI that reversed the actions of applied GABA is referred to as the low dose, and the dose that produced maximal effects without causing epileptiform bursting is referred to as the high dose.

Interaction of masking with iontophoretically applied glutamate and $\mathrm{KCl}$. In 2 experiments, the firing rate of recorded neurons was artificially elevated with glutamate or potassium $(\mathrm{KCl})$. In some cases, constant currents of glutamate were used to mimic the effects of BMI on spontaneous and evoked firing. The magnitude of the current was adjusted to bring the spontaneous activity to the desired level, and tests were performed while the current was maintained. In other cases, short pulses of either $\mathrm{KCl}$ or glutamate were ejected under computer control in order to mimic the effects of visual stimulation. In these cases, the current was chosen to bring the cell as close as possible to the average rate of firing during stationary visual stimulation. In most cases, it was necessary to make the current pulses somewhat longer than the visual stimuli with which they were being compared, because the cell's response to the applied glutamate or $\mathrm{KCl}$ had a slower time course.

\section{Results}

\section{Effects of BMI on the magnitude of spontaneous and evoked activity}

The effects of BMI were studied in 42 neurons that could be held for a period sufficient to allow full testing as described above. Contrary to some previous reports (Daniels and Pettigrew, 1975; Sillito, 1975b), no systematic differences were observed in the effects of BMI on cells classified as simple or complex, and therefore the results from both types of cells are considered together. Figure 1 illustrates the effects of applied 
GABA and BMI on visual responsiveness. Figure $1 A$ shows the response of one cell to a 200-msec flash of a stationary light bar in the absence of applied drugs. The cell's response to the same stimulus during iontophoresis of GABA at a current of $10 \mathrm{nA}$ is shown in $B$ : The response was essentially eliminated. Figure $1 C$ shows the response when $10 \mathrm{nA}$ of GABA and $16 \mathrm{nA}$ of BMI were applied concurrently. This dose was sufficient to just counteract the effects of the applied GABA: The response was about equal to that seen in $A$. At this dose of BMI, a 2-fold increase in the GABA current had little effect. Switching off the GABA current, however, did produce an elevation in the evoked and spontaneous activity (cf. Fig. $8 B$ ). Figure $1 D$ shows the response under the same conditions except that the BMI current was increased to $40 \mathrm{nA}$ : Both the visually evoked response and the spontaneous activity were increased (note the difference in scale). When the ejection currents were discontinued, the response of the cell (not shown) rccovered and was ncarly identical to that shown in $A$.

GABA suppressed the visual and spontaneous activity of each of 22 neurons tested. In each case, the effects were reversed by BMI. BMI alone increased the spontaneous and evoked activity in all 42 of the cells tested. Responses of 18 cells were fully tested before, during, and after both low and high ejection currents of BMI (see Materials and Methods). The effects of the 2 doses on spontaneous activity and peak firing rate (during visually evoked activity) are shown in Figure 2. Note that the low dose of BMI produced a substantial increase in both the spontancous and pcak evoked activity, and that the high dose produced further increases.

\section{Effects of BMI on direction and orientation tuning}

BMI had marked effects on the orientation and direction selectivity of nearly all cells tested. No systematic differences were noted in the effects on simple and complex cells. An example of the effects of BMI on orientation and direction selectivity is illustrated in Figure 3 for the same cell shown in Figure 1. Figure $3 A$ shows the results obtained prior to drug ejection. The orientation half-width and DI calculated from this tuning curve were $18^{\circ}$ and 0.13 , respectively. The tuning curve shown in $B$ was obtained after the low dose of BMI (16 nA). For this cell, there was very little broadening of the orientation half-width $\left(25^{\circ}\right)$, but a dramatic loss of direction selectivity (DI $=0.8$ ). When the ejection current was increased to $40 \mathrm{nA}$, the cell responded essentially equally to all directions of movement (Fig. $3 C$ ). After discontinuing the ejection current, the orientation and direction selectivity of the cell returned to normal $(D)$. Figure 4 shows the changes in orientation half-width and the DI that occurred in each of the 18 cells tested at both high and low BMI currents. Note that, for most cells, the loss of directional tuning occurred at the low dose. In contrast, the low dose produced only a moderate change in the orientation half-width of most cells (the mean changed from $33^{\circ} \pm 6^{\circ}$ to $57^{\circ} \pm 9^{\circ}$ ). Although a complete loss of orientation tuning was observed in most cells, it occurred only with long periods of high ejection currents. The effects of high BMI currents on orientation and direction selectivity were tested on a total of 35 neurons. The changes in orientation and direction selectivity are summarized for the entire sample in Figure 5.

The observations described above refer to the responses to moving stimuli. During the course of testing the effects of BMI on the orientation dependence of paired-pulse suppression (see below), 16 cells were tested with stationary stimuli at various
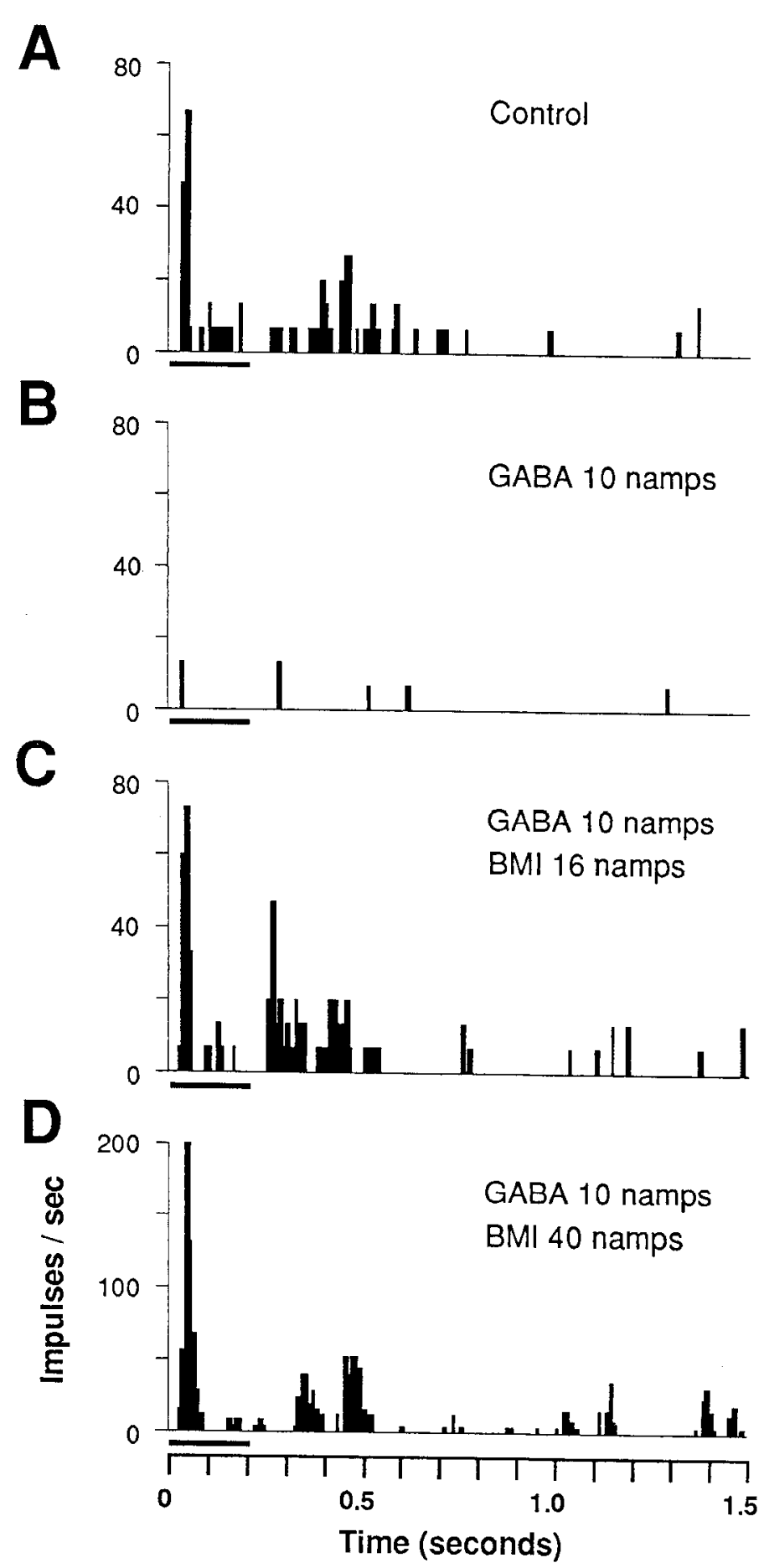

Figure 1. The effects of GABA and 2 doses of BMI on visual responsiveness. $A$, Visual response of a cortical complex cell to a $200-\mathrm{msec}$ flash of a light bar of optimal size and orientation. $B$, Response of the same cell to the same stimulus but during application of $10 \mathrm{nA} \mathrm{GABA}$. $C$, Response as in $B$ but during simultaneous application of $10 \mathrm{nA}$ GABA and 16 nA BMI (low dose). Note that the effects of the applied GABA are effectively antagonized by this current of BMI. A 2-fold increase in the GABA current (not shown) caused little change in responsiveness. $D$, As in $C$, but BMI current has been increased to $40 \mathrm{nA}$ (high dose). Further increases in BMI current produced abnormal bursting in this cell. Each histogram contains the summed responses to 20 trials. Bins are $10 \mathrm{msec}$. 

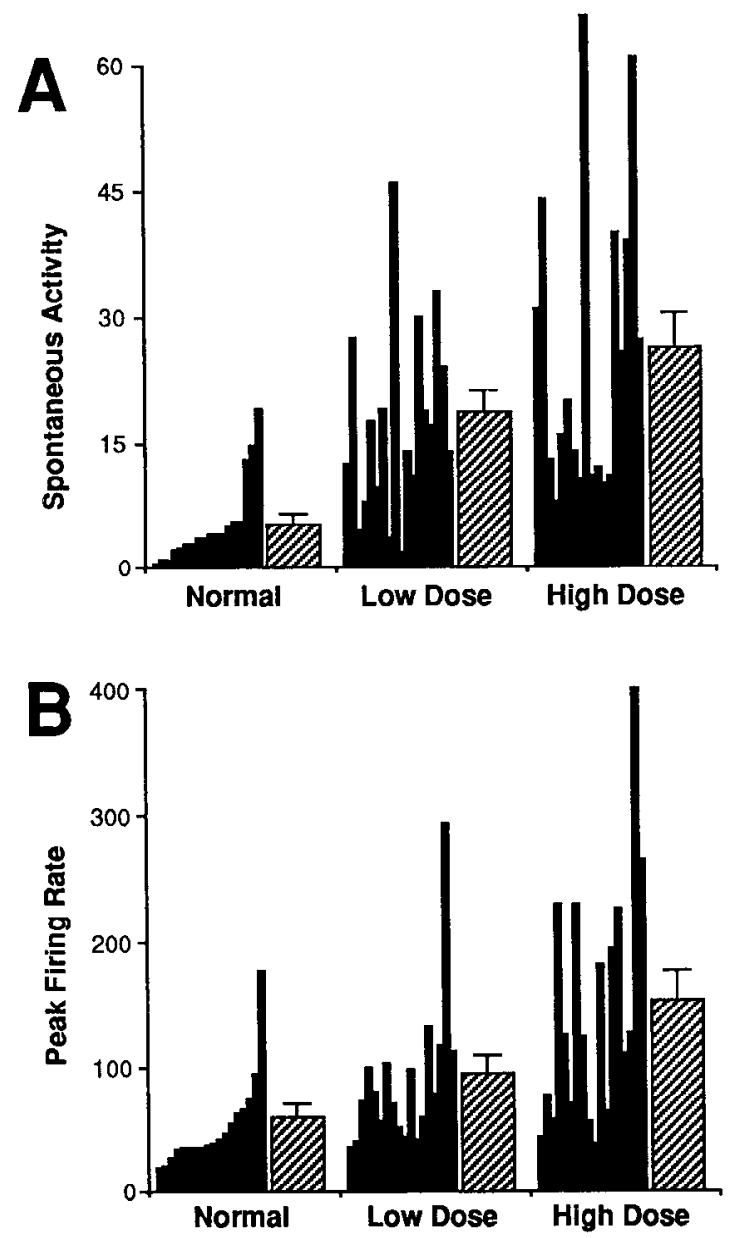

Figure 2. Effects of low and high ejection currents of BMI on spontaneous and visually evoked activity. $A$, Effects on spontaneous activity (measured during a separate period at the beginning and end of each temporal interaction and orientation test). $B$, Effects on peak visually evoked firing rate. Each histogram shows individual results (solid bars) and mean \pm SEM (hatched bars) for 18 cells tested before, during, and after 2 doses of BMI (low and high, defined as in Fig. 1 and Materials and Methods). The solid bars in corresponding positions (first through eighteenth) within each of the 3 conditions (normal, low dose, high dose) are results obtained from an individual cell.

orientations. Surprisingly, the effects of a high dose of BMI on orientation selectivity were much less dramatic when that selectivity was measured with stationary stimuli rather than moving stimuli. Most cells, when tested with high BMI currents, responded at least half as well to the orthogonal orientation as they did to the preferred orientation, if the bars were moving. When stationary stimuli were used, however, most cells continued to show a greatly reduced response to the orthogonal orientation, relative to the preferred. Figure 6 shows an example of the responses to stationary and moving stimuli obtained from the same cell using the same ejection currents of BMI. The responses to the moving stimuli were obtained first and show a complete loss of selectivity. The responses to stationary stimuli were obtained during a temporal interaction test performed right after the orientation/direction test. Although there is a response to the orthogonal stimulus, it is quite small relative to the preferred stimulus. Figure 7 shows the degree of broadening observed in 16 cells treated with high currents of BMI and tested

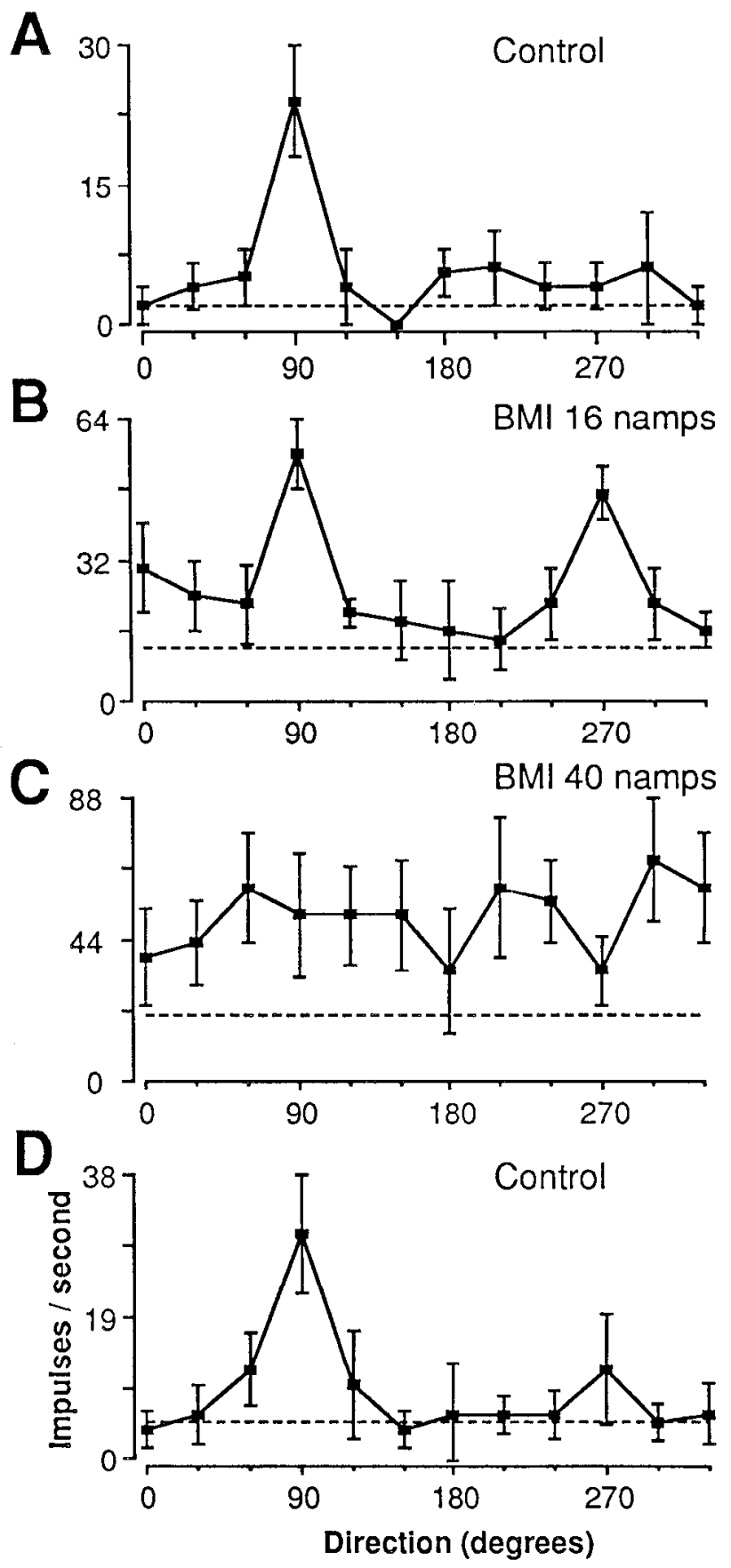

Figure 3. Example of BMI's effects on orientation and direction selectivity: responses of cell shown in Figure 1 to bars of optimal size $\left(8^{\circ}\right.$ $\left.\times 0.5^{\circ}\right)$ and speed $(5 \% \mathrm{sec})$ moved in each of 12 equally spaced directions. Tuning curves are constructed from the mean and SEM of 5 repetitions (solid lines with error bars). Dashed lines indicate spontaneous firing rate. $A$, Prior to ejection of BMI. $B$, During ejection of low (16 nA) current of BMI. Note elevation of spontaneous and evoked firing rates and loss of direction selectivity, but little effect on orientation selectivity. $C$, During ejection of high ( $40 \mathrm{nA})$ current of BMI. Note relatively cqual response to all directions. $D$, Ten min after cessation of BMI. Level of responsiveness and degree of orientation and direction selectivity have returned to values quite close to those in $A$.

with stationary stimuli. Comparison with Figure 4 reveals that the effects of $\mathrm{BMI}$ on orientation tuning were much less dramatic when cells were tested with stationary stimuli than with moving stimuli. 


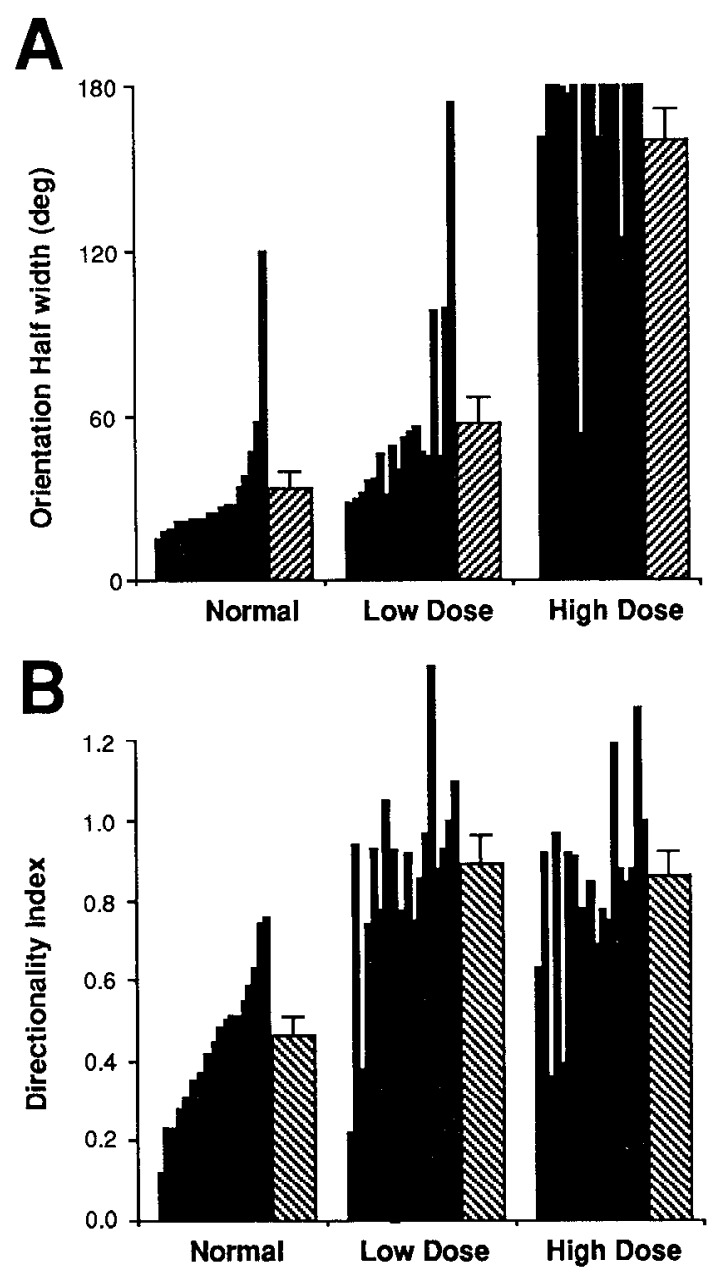

Figure 4. Effects of BMI on orientation and direction selectivity in 18 cells tested with low and high ejection currents. $A$, Effects on half-width at half-height of orientation tuning curves (like those shown in Fig. 3). Note the more modest effects of the low dose. $B$, Effects on DI (see Materials and Methods). Note the relatively equal effects of the low and high doses. All other conventions are as in Figure 2.

\section{Effects of BMI on paired-pulse suppression}

For most cells studied, the effects of BMI on paired-pulse suppression were much more modest than the effects on the magnitude of spontaneous and evoked activity and on selectivity for the orientation and direction of a moving stimulus. Figure 8 illustrates the results of temporal interaction tests performed on the same cell as is shown in Figures 1 and 3 . Figure $8 A$ shows the response obtained during a temporal interaction test performed prior to ejection of drugs. Note that the response to the test stimulus is suppressed relative to that of the identical condition stimulus that precedes it. This masking suppression persisted during ejection of $16 \mathrm{nA}$ of BMI (Fig. $8 B$ ) and during the higher dose of $40 \mathrm{nA}(C)$. Figure $8 D$ shows responses obtained $15 \mathrm{~min}$ after BMI was discontinued. The results obtained from 18 cells tested for paired-pulse suppression during both low and high BMI ejection currents are shown in Figure 9. Although there were several cells that showed a decrease in suppression under BMI (i.e., an increase in the temporal interaction index), a larger number of cells actually showed increased suppression under BMI (i.e., a decrease in the temporal interaction index).
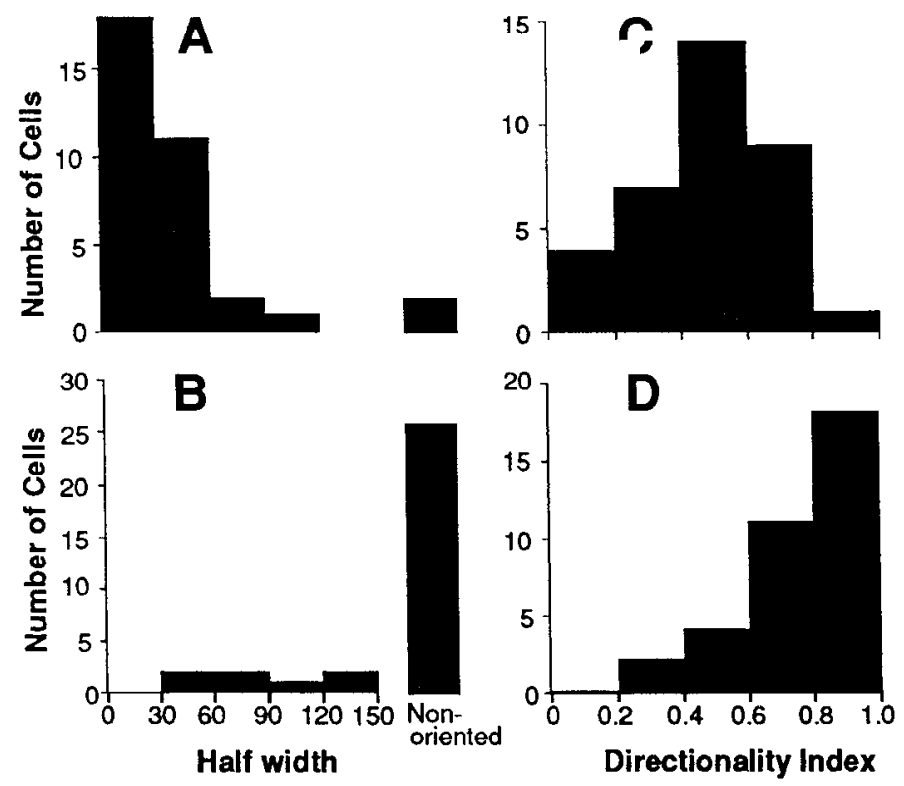

Figure 5. Effects of high BMI ejection currents on orientation and direction selectivity. Histograms show the half-widths $(A, B)$ and DIs $(C, D)$ obtained before $(A, C)$ and during $(B, D)$ ejection of high BMI currents $(30-120 \mathrm{nA})$ for all 35 cells tested. Data from 7 additional cells for which testing was incomplete have been excluded.

Two examples of this enhancement are shown in Figure 10. The histograms shown in Figure 10, $A$ and $B$, illustrate the response of one cell before $(A)$ and during $(B)$ a low dose $(20 \mathrm{nA})$ of BMI. At this dose of BMI, the evoked activity increased by about $50 \%$, and the spontaneous activity nearly doubled. Responses of a second cell are shown in Figure 10,C and $D$. This cell showed little paired-pulse suppression when tested at an ISI of $400 \mathrm{msec}$, prior to ejection of BMI. When tested at the same ISI, but during a high dose of BMI $(60 \mathrm{nA})$, the cell showed pronounced suppression.

A total of 42 cells were tested at the high dose of BMI, including the 18 cells shown in Figure 9 and 24 cells tested only at the high dose. Figure 11 summarizes the changes in pairedpulse suppression that occurred during the ejection of high BMI currents for all cells tested. For each cell, the value given is the temporal interaction index obtained prior to BMI minus the temporal interaction index obtained during BMI. Figure $11 \mathrm{~A}$ shows the results for temporal interaction tests performed with an ISI of $200 \mathrm{msec}$. Although the distribution is peaked near 0 , it is slightly skewed towards positive values. The mean temporal interaction index prior to BMI $(58.8 \pm 4.3)$ was, in fact, not significantly higher $(0.10>p>0.05$; 2-tailed paired $t$ test) than the mean temporal interaction index during BMI $(48.7 \pm 4.7)$. Figure $11 B$ shows the results for masking tests performed with an ISI of $400 \mathrm{msec}$. The enhancement of paired-pulse suppression under BMI was more marked for these tests. (Mean temporal interaction indices were $78.5 \pm 3.4$ prior to BMI and 58.5 \pm 4.8 during BMI; $p<0.001$; paired $t$ test). A smaller number of cells tested at an ISI of $600 \mathrm{msec}$ showed an enhancement of paired-pulse suppression that was intermediate between that seen at 200 and at $400 \mathrm{msec}$.

In 15 cells, the orientation dependence of paired-pulse suppression was assessed before, during, and after BMI. Three examples are shown in Figure 12. For 6 cells, like that shown in Figure $12 \mathrm{~A}$, BMI led to a broadening of the orientation selec- 


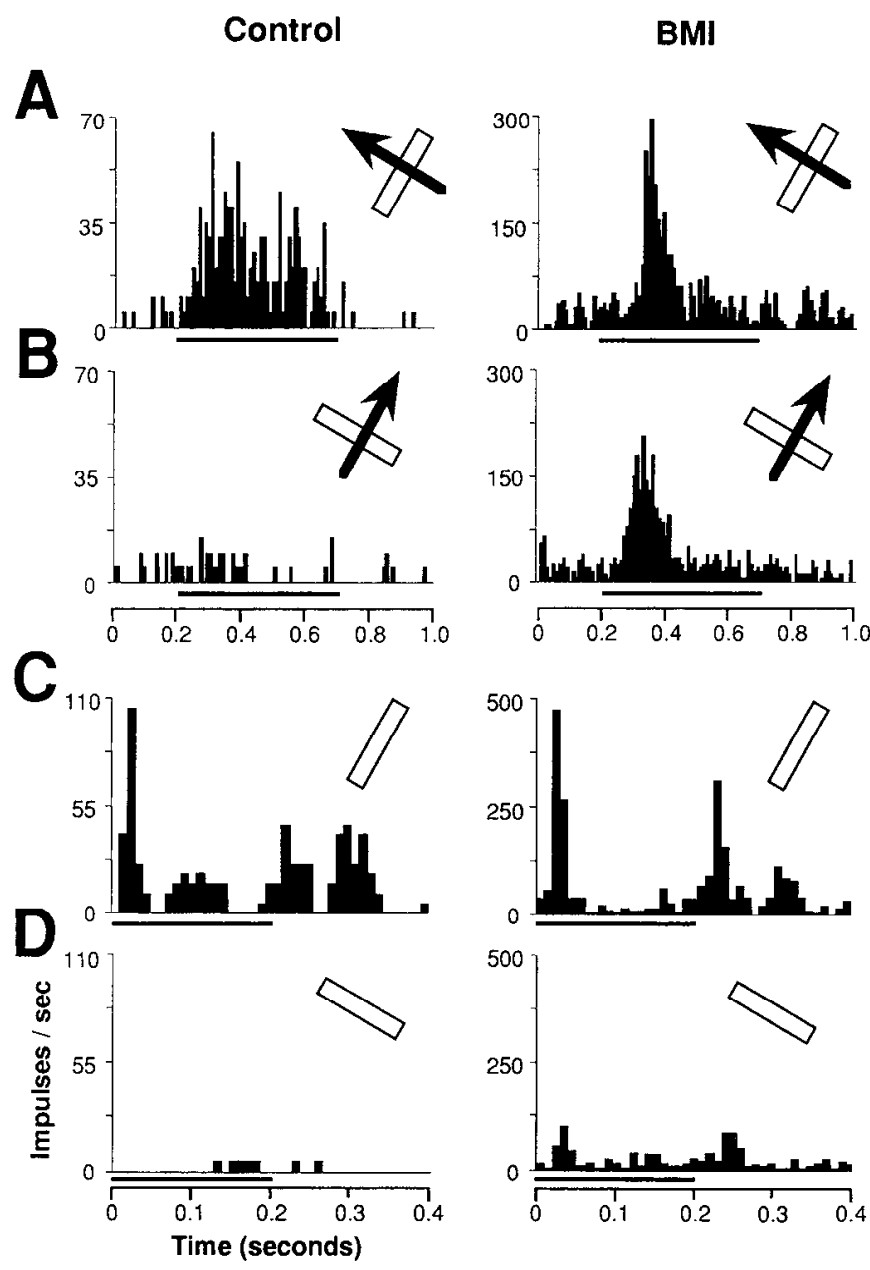

Figure 6. Example of differential effects of BMI on orientation tuning for moving and stationary stimuli. The left column of histograms shows responses obtained prior to BMI. The right column of histograms shows responses obtained during high ejection current of BMI $(85 \mathrm{nA})$. The stimulus is indicated in the upper right-hand corner of each histogram. Arrows indicate moving stimuli; bars without arrows indicate stationary stimuli. Note that a longer period is shown for the responses to moving stimuli $(1.0 \mathrm{sec})$ than for those to stationary stimuli $(0.4 \mathrm{sec})$. For all histograms, each bin is $10 \mathrm{msec}$. The stimulus markers below each histogram indicate the time during which the stimulus was present within the receptive field. $A$, Responses to preferred direction of movement. $B$, Responses to direction orthogonal to the preferred. $C$, Responses to stationary stimulus at preferred orientation. $D$, Responses to stationary stimulus at orthogonal orientation. Note that BMI appears to have a greater effect on the selectivity for moving stimuli ( $A$ vs. $B$ ) than for stationary stimuli ( $C$ vs. $D$ ).

tivity of the response to the condition stimulus, but little change in depth or tuning of the suppression. The cell shown in $B$ was unusual in that the magnitude of the suppression decreased. For this cell, the tuning of both the condition response and the suppression of the test response broadened. This was true of 7 cells tested, though for most cells, the change in the excitatory tuning (measured from the condition response) was greater than the change observed in the suppressive tuning curve. In the remaining 2 cells tested, the excitatory half-width increased, but there was actually a small decrease in the suppressive half-width. As noted above, some cells showed an increase in paired-pulse suppression under BMI. The cell shown in Figure $12 C$, for example, showed only minimal suppression when tested prior to $\mathrm{BMI}$ or after recovery from BMI, but displayed a broadened

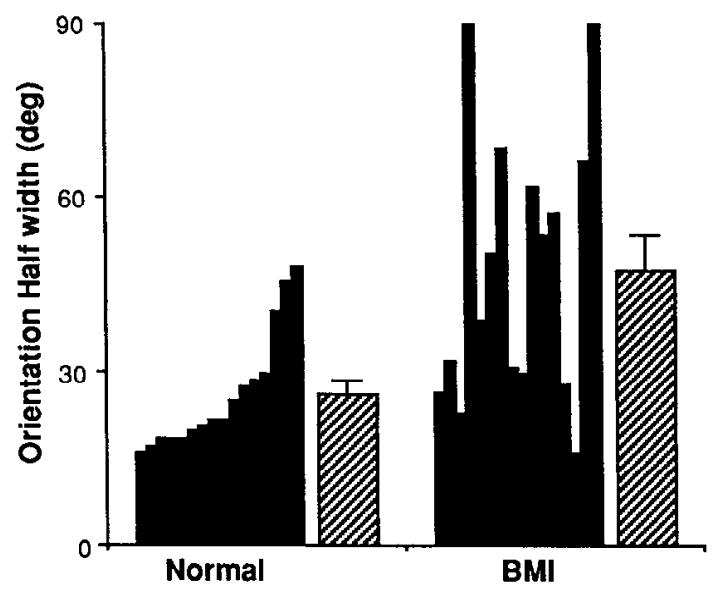

Figure 7. Effects of high BMI currents on orientation selectivity for stationary stimuli: individual observations (solid bars) and mean \pm SEM (hatched bars) for 16 cells tested with stationary stimuli presented at 6 equally spaced orientations. Half-widths were calculated as for moving stimuli except that the maximum half-width was $90^{\circ}$ instead of $180^{\circ}$. (Note that assigning a value of $180^{\circ}$ to the 2 cells shown as having halfwidths of $90^{\circ}$ during BMI would increase the mean half-width only $11^{\circ}$.) Other conventions are as in Figures 2 and 4 . Note that the increase in half-width is less when measured with stationary stimuli than when measured with moving stimuli. All but 1 of the cells included in this histogram were also tested with moving bars (data included in Fig. 5). Comparison with Figure 5 reveals that the increase in half-width observed during high currents of BMI is less when measured with stationary stimuli than when measured with moving stimuli.

excitatory response and powerful suppression when tested during BMI ejection.

In summary, BMI had its greatest effects on the responses to moving stimuli, smaller effects on the orientation selectivity of the response to stationary stimuli, and minimal effects on the magnitude and orientation dependence of paired-pulse suppression.

\section{Interactions between paired-pulse suppression and pharmacological excitation}

In 6 cclls, the cffects of clevatcd discharge rate on paired-pulse suppression and orientation and direction selectivity were tested by iontophoresing glutamate at levels that mimicked the increase in discharge produced by BMI. In no case did the glutamate alter the degree of suppression exhibited by the cell. Orientation and direction selectivity were not tested quantitatively under these conditions, but qualitative testing revealed no obvious changes in receptive field organization. Previous studies have also reported that elevation of spontaneous activity does not, in and of itself, alter the selectivity of cortical neurons (Sillito, 1979).

A question of more direct relevance to understanding the mechanism of paired-pulse suppression was whether or not one or more components of the effect could be mimicked using pulses of glutamate or $\mathrm{KCl}$ instead of visual stimuli to excite a cortical neuron. Three different mechanisms that could conceivably underlie paired-pulse suppression lead to different predictions about the effect of replacing either the condition or the test visual stimulus with a pharmacological stimulus. First, if the suppression results from a postsynaptic process that is directly coupled to the degree of postsynaptic excitation (e.g., inactivation of $\mathrm{Na}^{+}$conductances, or afterhyperpolarization), then the suppression of the response to a visual test stimulus 

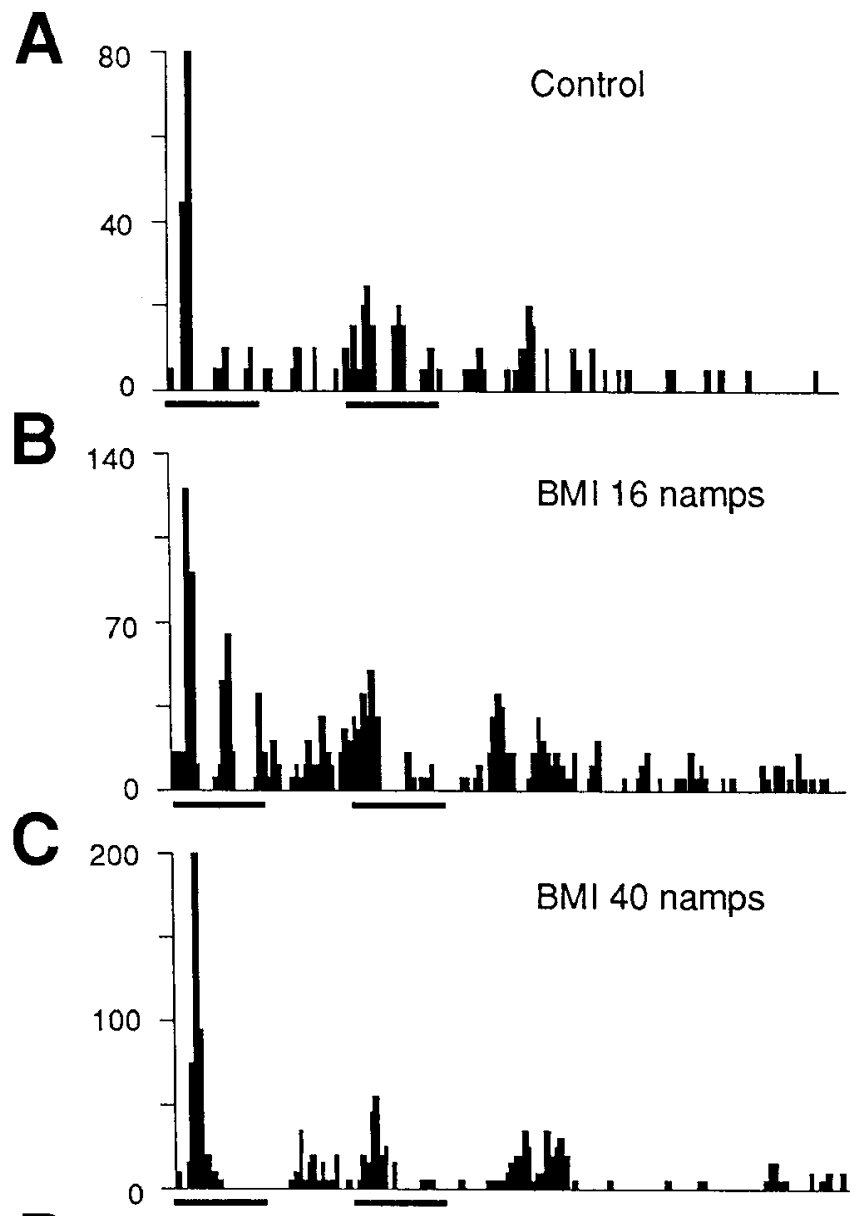

D)

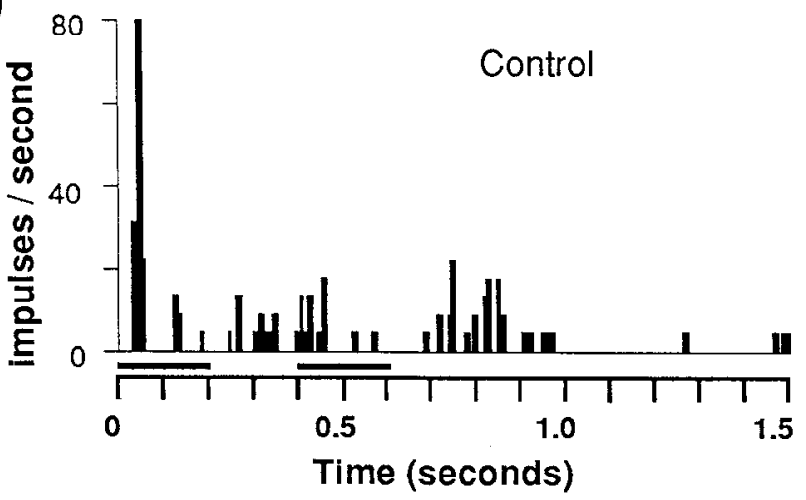

Figure 8. Example of paired-pulse suppression before, during, and after BMI: temporal interaction tests performed on same neuron shown in Figures 1 and 3. Condition and test stimuli were $200-\mathrm{msec}$ flashes (indicated by stimulus markers below each histogram) of an optimally oriented light bar. $A$, Temporal interaction test performed prior to BMI ejection. Note the reduction of the initial on transient in the response to the test stimulus (second stimulus) as comparcd to the response to the condition stimulus (first stimulus). $B$, Temporal interaction test performed during low dose (16 nA) of BMI. Suppression of test response is slightly less than in $A$, but still evident. $C$, Temporal interaction test performed during high dose $(40 \mathrm{nA})$ of BMI. $D$, Temporal interaction test performed $15 \mathrm{~min}$ after cessation of BMI.

should be equivalent regardless of whether the condition stimulus is visual or a pulse of glutamate or $\mathrm{KCl}$. Second, if the suppression results from a visually activated postsynaptic inhibitory process, it might be expected that, following a visual condition stimulus, the sensitivity to iontophoresed glutamate

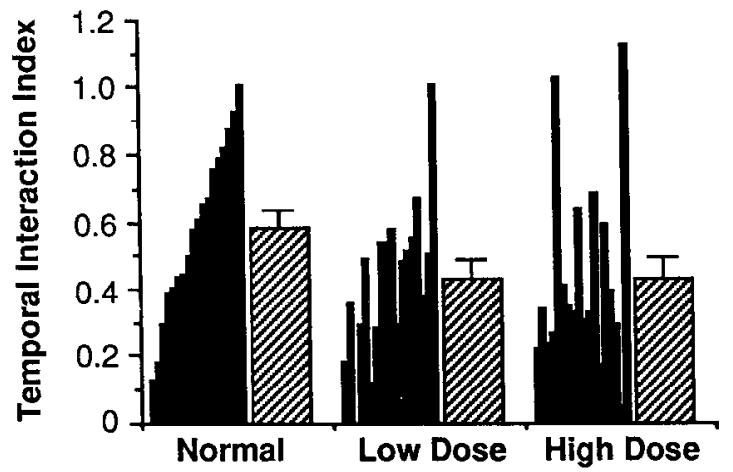

Figure 9. Effects of low and high BMI ejection currents on pairedpulse suppression. Temporal interaction indices (see Materials and Methods) were obtained from 18 cells tested at a condition-test ISI of $200 \mathrm{msec}$ before and during low and high ejection currents of BMI. Conventions are as in Figures 2, 4, and 7. Hatched bars show mean \pm SEM; solid bars show individual observations.

or $\mathrm{KCl}$ should be reduced by an amount comparable to that by which the response to a visual test stimulus is reduced. Thus, in this case, there should be no suppression following a pharmacological condition stimulus, but following a visual condition stimulus, there should be equal suppression of a visual or pharmacological test stimulus. Finally, if the suppression results from a presynaptic process, it should occur only when the condition and test stimuli are both visual and activate the same presynaptic pathway; postsynaptic activation of the cell with potassium or glutamate should fail to suppress a subsequent visual test stimulus and should itself not be suppressed by a preceding visual condition stimulus.

The effect of replacing the visual condition stimulus with a pulse of glutamate was tested in 7 neurons, all of which showed suppression when tested with visual stimuli. In most cases, the glutamate pulse had to be longer than the visual stimulus in order to achieve a similar peak response. In each case, there was no suppression of the test response by a preceding pulse of glutamate, and in 4 cases, there was enhancement. An example is shown in Figure 13. The cell showed pronounced paired-pulse suppression when tested with visual stimuli. When the visual test stimulus was preceded by a $1-\mathrm{sec}$ pulse of glutamate $(60$ $\mathrm{nA}$ ), however, the response was enhanced rather than suppressed, despite the fact that the glutamate produced an excitatory response of comparable magnitude to that produced by the visual condition stimulus.

The converse experiment, replacing the test rather than the condition stimulus with a pulse of glutamate, was performed in 10 neurons. In 4 additional cells, the test stimulus was replaced by a pulse of $\mathrm{KCl}$. Each of these 14 cells showed suppression when the test stimulus was visual, but in every case, there was no suppression of the response to the pulse of glutamate or $\mathrm{KCl}$. An example of one of the cells tested with $\mathrm{KCl}$ is shown Figure 14. The results of these tests indicate that excitability at the region of the cell stimulated by the iontophoretic pulse (presumably the soma) remains essentially unchanged during the period when visual responses are profoundly suppressed.

\section{Discussion}

Effects of BMI on the excitability and stimulus selectivity of cortical neurons

The effects of iontophoretically applied BMI on cortical orientation and direction selectivity observed in the present study 


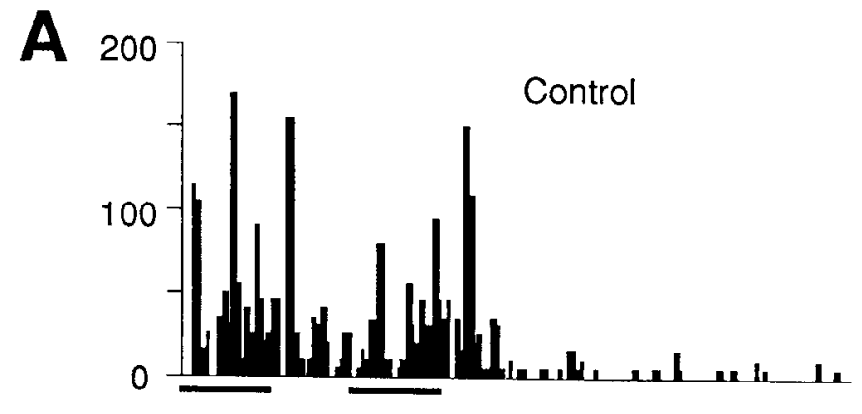

B
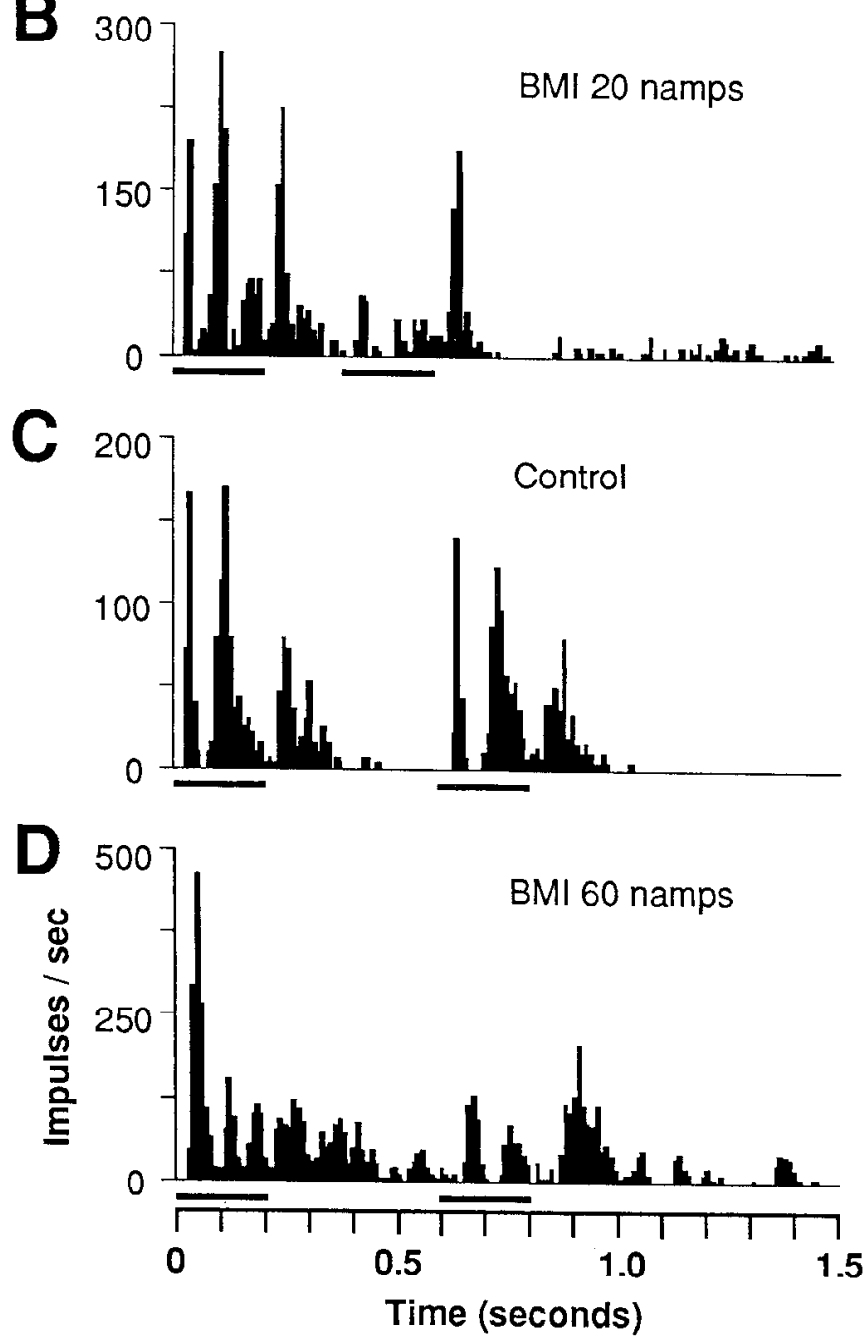

Figure 10. Two examples of enhancement of paired-pulse suppression during BMI ejection. $A$ and $B$, Results from 1 cell tested at an ISI of $200 \mathrm{msec}$. Testing prior to BMI ejection revealed only weak suppression $(A)$. Suppression was greatly enhanced during ejection of $20 \mathrm{nA}$ of BMI. $C$ and $D$, Temporal interaction tests performed on another cell at an ISI of $400 \mathrm{msec}$. $C$, Prior to BMI. $D$, During $60 \mathrm{nA}$ of BMI. Other conventions are as in Figure 8.

were, for the most part, in agreement with previous reports (Daniels and Pettigrew, 1973, 1975; Blakemore and Rose, 1974; Sillito, 1975a,b, 1979; Tsumoto et al., 1979; Sillito et al., 1980b). BMI disrupted direction selectivity and broadened or abolished orientation selectivity. In addition to these effects, it elevated the spontaneous and peak evoked discharge rates. Despite these general similarities, however, there were important differences between the present results and those previously reported. First
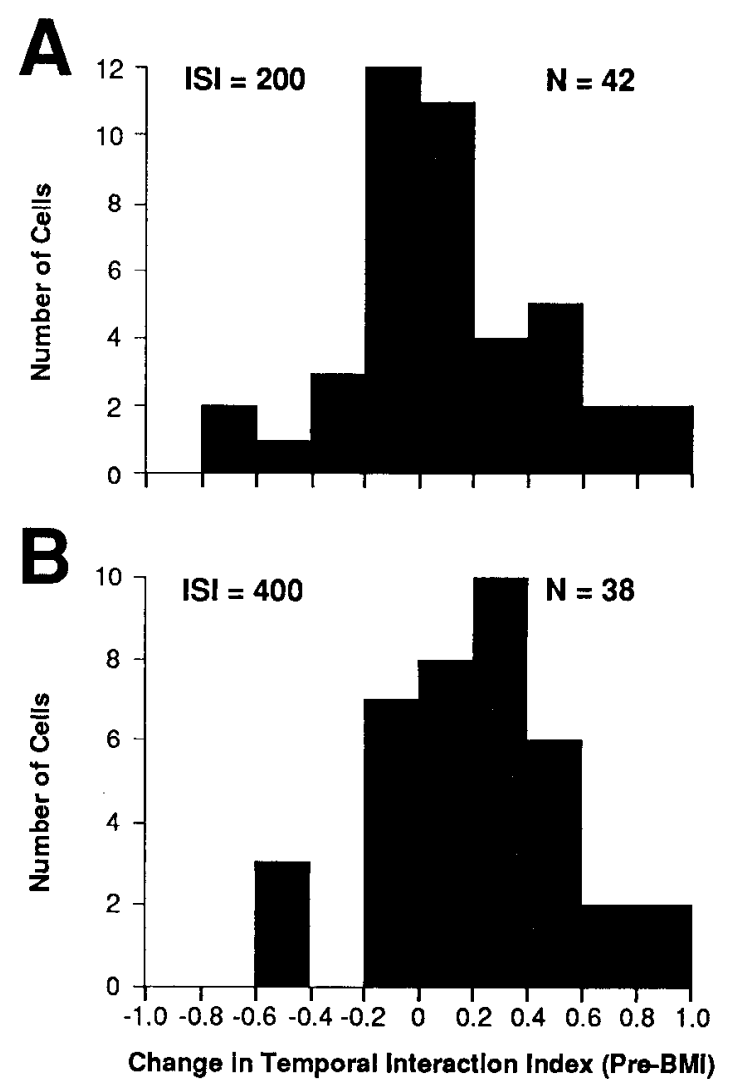

Figure 11. Change in temporal interaction indices during high BMI ejection currents. Histograms show the differences in index (normal high dose BMI) for all cells tested. A value of 0 indicates no change; positive values indicate increased suppression during BMI, and negative values indicate decreased suppression during BMI. $A$, Results of 42 cells tested at an ISI of $200 \mathrm{msec}$. $B$, Results from 38 of the cells shown in $A$ that were also tested at an ISI of $400 \mathrm{msec}$.

of all, BMI had much more modest effects on cortical orientation selectivity when currents were restricted to those that antagonized the effects of applied GABA. Although there was, on average, nearly a 2 -fold increasc in the half-width of the orientation tuning curve at this dose, orientation selectivity was completely eliminated in only 1 out of 18 neurons tested. In this respect, the present results agree with early reports from Blakemore and Rose (1974) and Sillito (1975b), but disagree with several later reports (Sillito, 1979; Sillito et al., 1980b), which have reported a higher proportion of cells whose orientation selectivity was abolished. One possible interpretation of this disagreement is that the partial, rather than complete, loss of orientation selectivity reflects an incomplete blockade of $\mathrm{GABA}_{\mathrm{A}}$ receptors. In this view, the more complete loss of orientation tuning observed after higher ejection currents was due to a more effective blockade of inhibition. It is also possible, however, that the effects seen at the high currents reflect a pathological hyperexcitable state. Indeed, the high currents of BMI used in the present study were just below those necessary to evoke epileptiform bursting. Resolution of this issue hinges on the question of whether or not visual stimuli can evoke IPSPs in cortical neurons during ejection of BMI currents sufficient to block the effects of iontophoretically applied GABA.

The present study employed larger increments in orientation $\left(30^{\circ}\right)$ and smaller numbers of repetitions (5) than have been employed in some prior studies. This precludes detailed analyses 
Normal

A

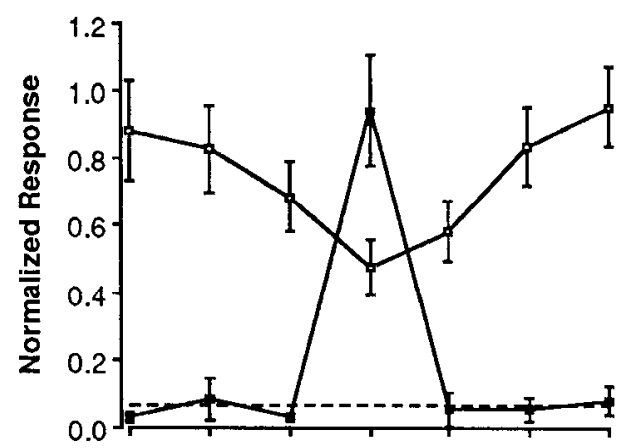

B

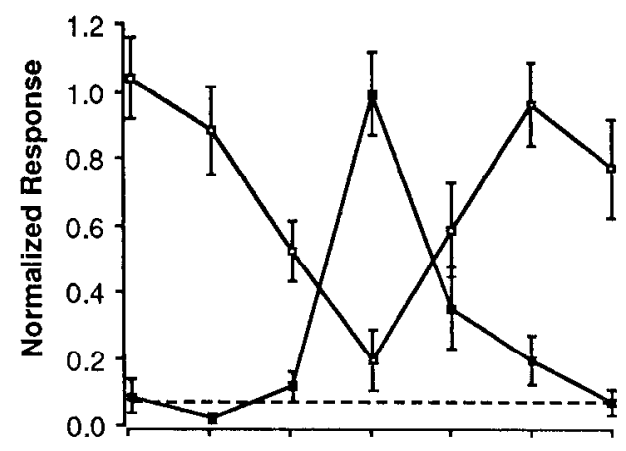

C

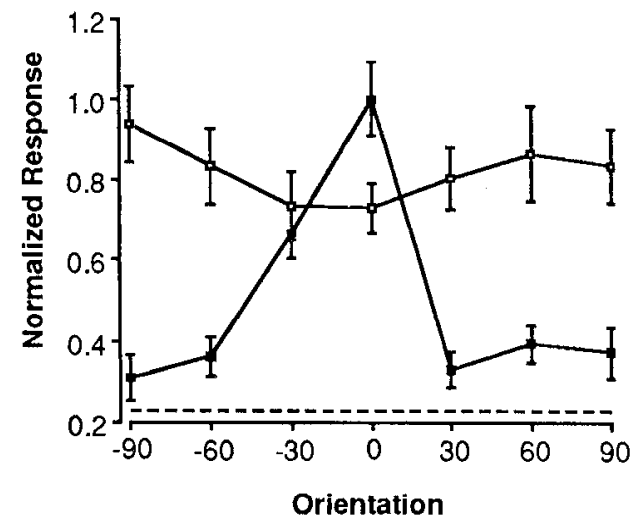

BMI
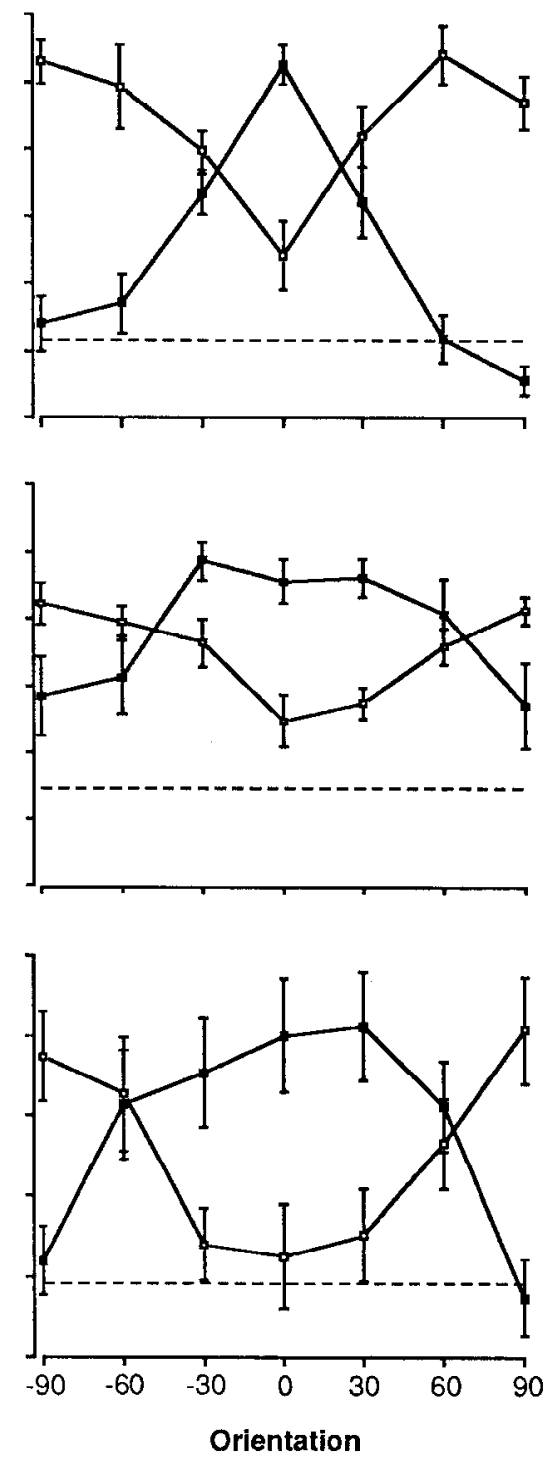

Figure 12. Effects of BMI on orientation dependence of paired-pulse suppression. Orientation dependence of paired-pulse suppression was tested by varying the orientation of the condition stimulus in $30^{\circ}$ increments while keeping the test stimulus at the preferred orientation. Solid symbols indicate response to condition stimulus. Open symbols indicate responses to test stimulus. Dashed lines indicate spontaneous fring rate. Responses within each graph were normalized to the response to the test stimulus presented alone. Orientation of the condition stimulus is shown below each graph. Three graphs on the left-hand side werc obtaincd from 3 different cells prior to BMI delivery. Three graphs on the right-hand side were from the same cells during ejection of high BMI currents. Tuning for the condition stimulus response broadened for all 3 cells. Tuning for the suppression remained relatively unchanged in $A$, became broader and shallower in $B$, and became deeper in $C$. of the fine structure of the resulting tuning curves and may have led to a slight underestimation of the sharpness of tuning of the most selective neurons, but the impact on the observed results would be expected to be subtle relative to the dramatic effects observed with BMI.

An important difference between the present results and those previously described is that the effects of BMI on orientation selectivity were much less marked when stationary stimuli were used than when moving stimuli were used. Previous studies have all used moving stimuli. Because moving stimuli traverse a greater part of the visual field, they are likely to result in a more widespread activation of cortical neurons than are stationary stimuli. This may allow for a greater degrce of mutual excitation between cortical neurons tuned to different orientations and, hence, a consequent exaggeration of the effects of BMI on orientation selectivity.

Another effect of BMI observed in the present study was the disruption of direction selectivity. These effects differed from the effects on orientation in that they were fully expressed at the lower of the 2 doses of BMI used. This is consistent with at least one previous report (Tsumoto et al., 1979) that direction selectivity is more sensitive to the effects of BMI than is orientation selectivity.

\section{The mechanism of orientation-selective suppression}

In an accompanying paper, it was shown that orientation-selective suppression in the visual cortex cannot be accounted for by subcortical mechanisms (Nelson, 1991b). The present study has demonstrated that the suppression persists, and is even enhanced, following both low and high ejection currents of BMI. BMI is, of course, limited in its spectrum of action. It blocks only postsynaptic inhibition mediated by fast, chloride-dependent $G A B A$ receptors, known as $G_{A B A}$ receptors. GABA also activates a second class of receptors, known as $G_{A B A}$ receptors, which appear to be located both presynaptically, where they mediate decreased transmitter release (Bowery et al., 1980), and postsynaptically, where they mediate a long-duration, potassium-dependent IPSP (Dutar and Nicholl, 1988). Although 
Figure 13. Failure of iontophoretically applied glutamate to cause suppression. Histograms on the left side demonstrate the depth and time course of paired-pulse suppression for one neuron. Condition and test stimuli were 200 -msec flashes of an optimally oriented bar (solid stimulus markers below histograms). Histograms on the right side illustrate responses obtained when the visual condition stimulus was replaced with a 1-sec pulse of $60 \mathrm{nA}$ glutamate (indicated by dashed lines below histograms). In $A$, the visual test stimulus was presented alone. In the remaining histograms, the test stimulus was preceded by a visual (left) or iontophoretic (right) stimulus with an ISI of $200(B), 400(C)$, or $600(D) \mathrm{msec}$. Note that the test response is suppressed at all ISIs when preceded by a visual condition stimulus, but is enhanced by a preceding glutamate pulse.
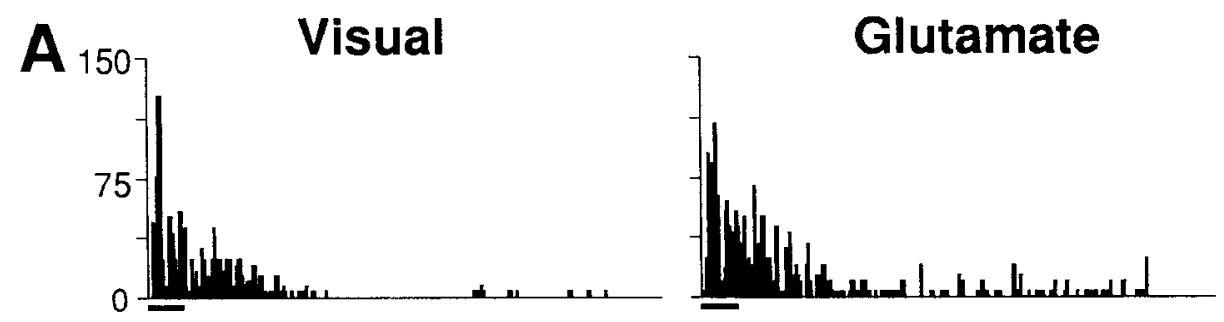

B
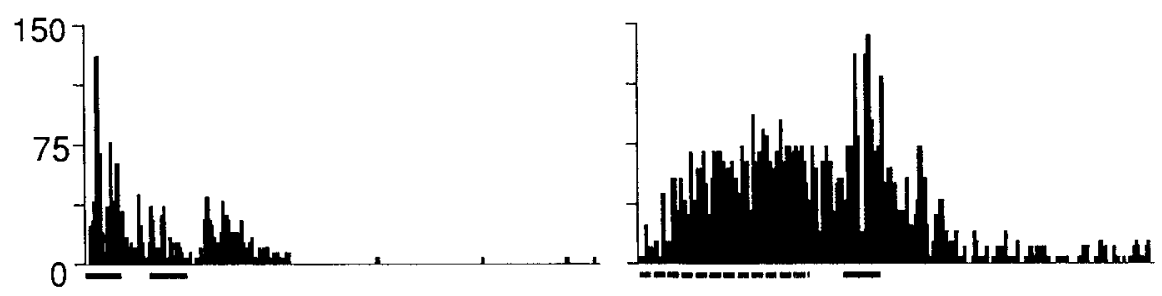

C
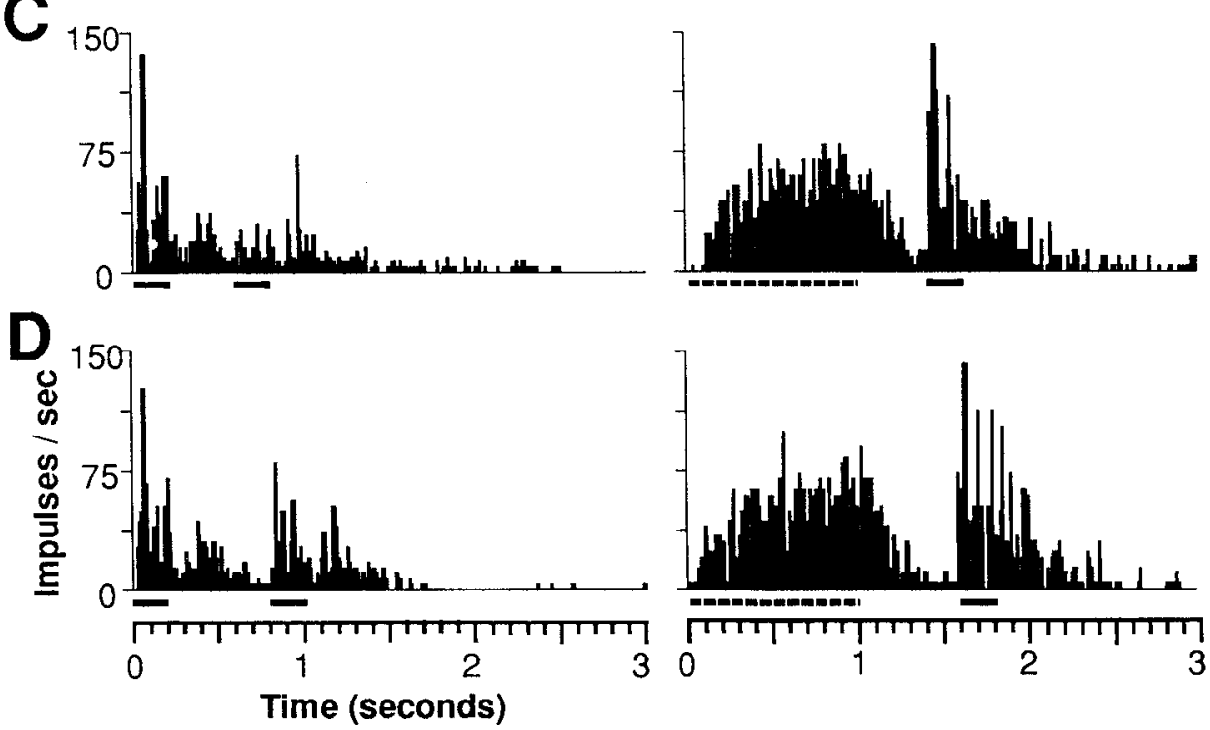

the BMI experiments rule out the involvement of $\mathrm{GABA}_{\mathrm{A}}$ receptors in masking suppression, they leave open the possible involvement of the $\mathrm{GABA}_{\mathrm{B}}$ receptor. Recently, the drug phaclofen has been found to be a specific antagonist for this receptor (Kerr et al., 1987; Dutar and Nicholl, 1988). In the visual cortex, phaclofen has been reported to have mixed excitatory and inhibitory effects on visually evoked activity, but apparently does not alter direction or orientation selectivity (Baumfalk and Albus, 1988). Unfortunately, results of preliminary experiments designed to test the possibility that phaclofen might block pairedpulse suppression have uncovered irreversible, deleterious effects of the drug on the responsiveness of cortical neurons ( $S$. B. Nelson, unpublished observations). Another related compound (Kerr et al., 1988) may perhaps prove more favorable for this type of experiment.

The reason for the enhancement of paired-pulse suppression seen following BMI application is unclear. Interestingly, previous studies have reported enhancement of presumed $\mathrm{GABA}_{\mathrm{B}}$ mediated IPSPs following blockade of GABA A $_{\mathrm{A}}$ receptors (Newberry and Nicholl, 1984; Hirsch and Burnod, 1987). The reason for this effect is not understood. Two possibilities mentioned in the studies cited above are, first, that blockade of $\mathrm{GABA}_{\mathrm{A}}$ receptors leads to an increase in the amount of GABA available to stimulate $\mathrm{GABA}_{\mathrm{B}}$ receptors, or second, that GABAergic interneurons are themselves inhibited via $\mathrm{GABA}_{\mathrm{A}}$ receptors and are thus disinhibited by blockade of those receptors. It is not known whether a similar enhancement occurs for the presynaptic effects of $\mathrm{GABA}_{\mathrm{B}}$ receptors.

A second finding of the present study that bears upon the question of mechanism is that suppression is not accompanied by a reduction in the response to iontophoretically applied glutamate or $\mathrm{KCl}$. This means that, during paired-pulse suppression, the excitability of the soma remains largely unchanged. The most straightforward interpretation of this result is that paired-pulse suppression is a presynaptic effect, perhaps occurring at the geniculocortical synapse. The possibility remains, however, that the mechanism is postsynaptic, but that it does not result in a hyperpolarization of the cell body. One such mechanism is the so-called "silent" or "shunting" inhibition (see Koch and Poggio, 1985). The receptor type that has been hypothesized to mediate shunting inhibition (Sherman and Koch, 1986), however, is precisely that which was blocked in the present experiments: the $\mathrm{GABA}_{\mathrm{A}}$ receptor.

The hypothesis that paired-pulse suppression is presynaptic in origin is quite consistent with the spatial specificity of the effect observed in an accompanying paper (Nelson, 1991a). A 


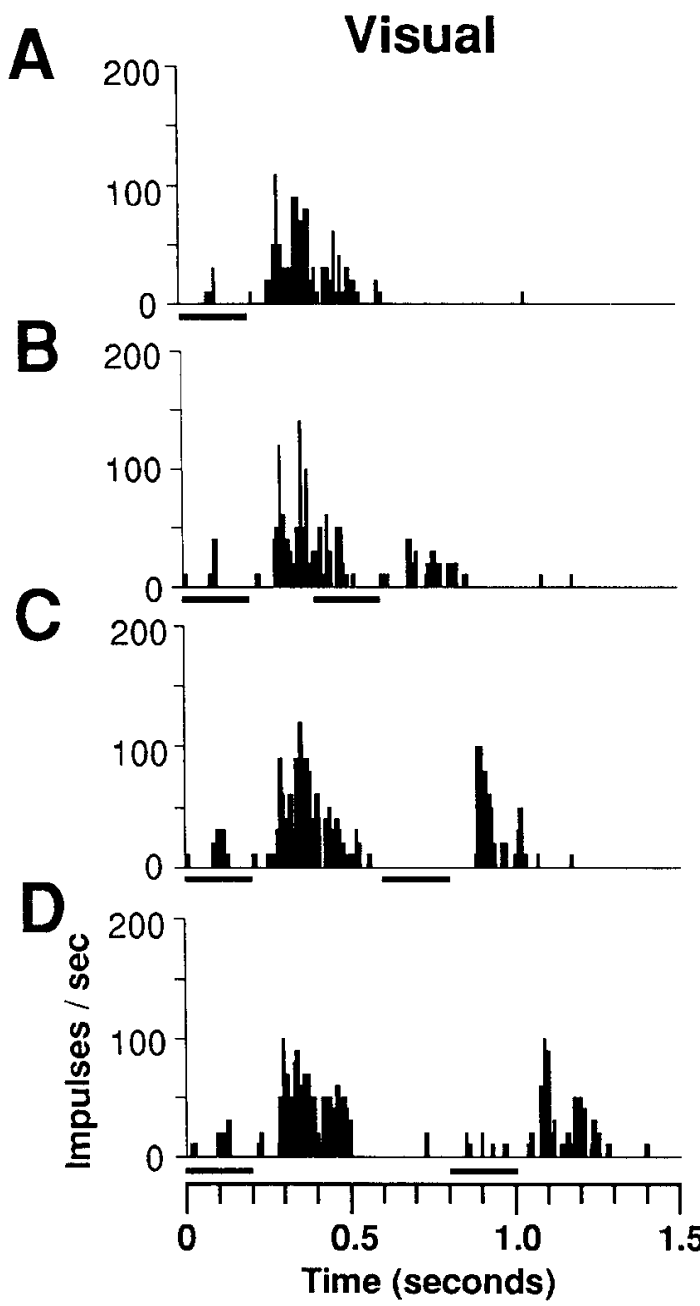

\section{Potassium}
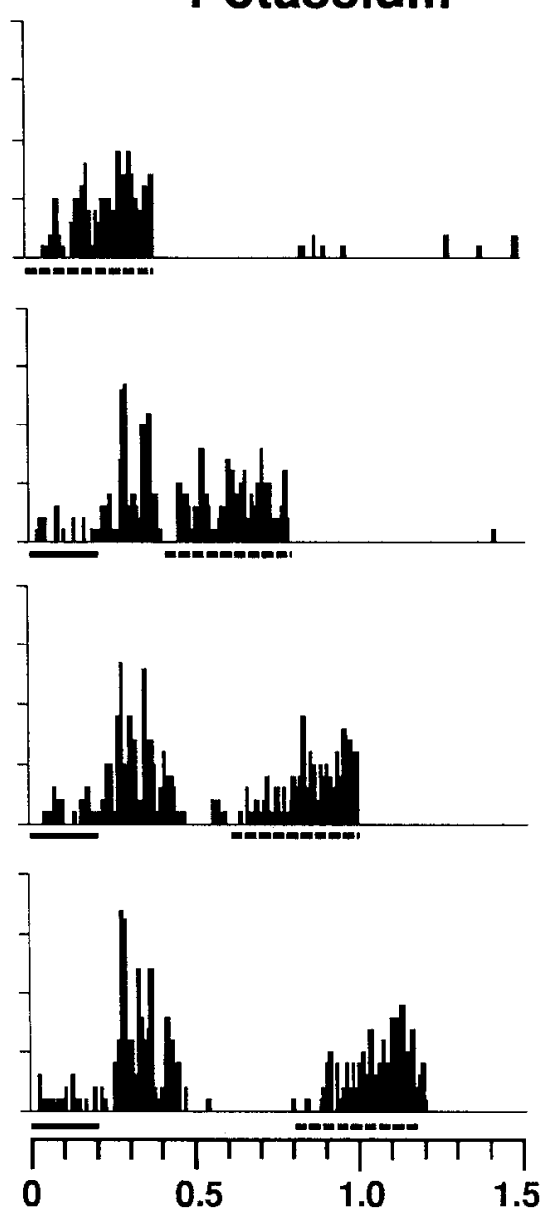

Figure 14. Lack of effect of visual condition stimulus on response to iontophoretically applied $\mathrm{KCl}$. The left histograms show result of a temporal interaction test. The right histograms illustrate results obtained when the visual test stimulus was replaced with a 400-msec pulse of $50 \mathrm{nA} \mathrm{KCl}$ (dashed lines below histograms). Solid stimulus markers below histograms indicate visual stimuli. $A$, Responses to visual (left) and $\mathrm{KCl}$ (right) test stimuli when presented alone. $B-D$, Test stimuli are preceded by a visual condition stimulus at ISIs of $200(B), 400(C)$, and $600(D)$ msec. This cell showed suppression at all ISIs when the test stimulus was visual, but no suppression when the test stimulus was a pulse of $\mathrm{KCl}$. condition stimulus presented at one location within a cell's receptive field frequently does not suppress the response to a test stimulus at another location. Such behavior might be expected if the different receptive field regions were fed by different inputs. Also, suppression is often prominent during the tail end of the cell's response to the condition stimulus, a time when the cell is firing well above spontaneous rates and hence presumably is not hyperpolarized. The idea of a presynaptic mechanism is also consistent with the present observation that depolarization of the postsynaptic cell with a "condition stimulus" consisting of a glutamate pulse failed to mimic the suppressive effects of a visual condition stimulus. This type of experiment provides further evidence that paired-pulse suppression is not due to some form of fatigue of the postsynaptic cell. Taken together, these observations argue strongly for a presynaptic, rather than postsynaptic, mechanism. Candidate mechanisms include presynaptic inhibition (Bowery et al., 1980) and presynaptic depression (for review, see Zucker, 1989), both of which have been well described in a number of brain regions. Interestingly, the psychophysical studies that predicted the existence of effects similar to the suppression demonstrated in this and a previous paper suggested that the mechanism might be presynaptic. This suggestion was made to account for the fact that the inhibitory effect appeared to be divisive, rather than subtractive, in nature; that is, it seemed to involve a decrease in the gain of excitatory inputs (Carpenter and Blakemore, 1973).

\section{The function of orientation-selective suppression}

Psychophysical studies that provided evidence for the existence of lateral inhibition in the orientation domain have, for the most part, argued that the function of such inhibition is to sharpen the orientation tuning of cortical neurons. Early reports on the effects of bicuculline in the cortex interpreted the observed broadening of orientation tuning as confirmation of the lateral inhibition hypothesis (Blakemore and Rose, 1974; Sillito, 1975b, 1977). More recently, intracellular recording has confirmed the idea that cortical IPSPs are tuned to the cell's preferred orientation, but has challenged the idea that the IPSPs are more broadly tuned, as would be required for them to contribute to sharpening orientation selectivity (Ferster, 1986). The orientation-selective suppression observed in this and an accompanying paper (Nelson, 1991a) has many of the features of the psychophysically predicted lateral inhibition. It is spatially localized, has a time course in the range of hundreds of milliseconds, and has an orientation tuning that is broad but centered on that most preferred by the cell. The present results have shown, however, that currents of BMI that broaden orientation tuning for stationary stimuli and eliminate orientation tuning for moving stimuli leave the suppression largely unchanged. Hence, it seems unlikely that the suppression plays an important role in sharpening orientation selectivity. The possibility remains, of course, that the suppression is necessary for normal 
orientation selectivity, but it is clearly not sufficient to produce normal selectivity in the absence of $\mathrm{GABA}_{\mathrm{A}}$-mediated inhibition. In either case, the finding that orientation selectivity is dissociable from orientation-selective suppression suggests that much of the evidence supporting the lateral inhibitory model may need to be reinterpreted. It is quite possible that lateral inhibition is a general property of the cortex, but that it plays little role in generating orientation selectivity.

If sharpening orientation selectivity is not the primary function of paired-pulse suppression, what is? A likely possibility, raised in an accompanying paper (Nelson, 1991a), is that the suppression reflects the operation of a gain-control mechanism designed to prevent saturation of neuronal responses. Such a mechanism may also serve to make cortical neurons more selective for moving stimuli than for stationary or flickering ones. Viewed in this way, the suppression allows cortical neurons to integrate different inputs over space and time, but prevents this integration from being saturated by a single repetitively stimulated input. Because of its shorter time course (hundreds of milliseconds vs. seconds), paired-pulse suppression is envisaged to be different from, but analogous in function to, the previously described gain-control mechanism underlying contrast adaptation (Ohzawa et al., 1982). Like paired-pulse suppression, contrast adaptation is orientation selective and spatially localized (Marlin and Cynader, 1987) and is not blocked by BMI (DeBruyn and Bonds, 1986). Despite these similarities, however, the 2 processes are likely to be different in mechanism. They have, as noted above, different time courses; they can appear separately or together in the responses of any given neuron (Nelson, 1991a). Furthermore, preliminary results of ongoing iontophoretic experiments indicate that the potassium channel blocker 4-aminopyridine (4-AP), which is known to block adaptation of repetitive firing in the superior colliculus in vitro (Llinas and Lopez-Barneo, 1988), also appears to block adaptation to visual stimulation in cortical neurons, but has no effect on paired-pulse suppression. Assuming the mechanism of 4-AP is the same in the cortex as it is in the superior colliculus, paired-pulse suppression and contrast adaptation appear to be due to complementary pre- and postsynaptic mechanisms acting in concert to adjust the gain of geniculocortical transmission.

\section{References}

Baumfalk U, Albus K (1988) Phaclofen antagonizes baclofen-induced suppression of visually evoked responses in the cat's striate cortex. Brain Res 463:398-402.

Blakemore C, Rose D (1974) Effects of bicuculline on functions of inhibition in visual cortex. Nature 249:375-377.

Blakemore C, Carpenter RHS, Georgeson MA (1970) Lateral inhibition between orientation detectors in the human visual system. Nature 228:37-39.

Bowery NG, Hill DR, Hudson AL, Doble A, Middlemiss J, Shaw J, Turnbull M (1980) (-)Baclofen decreases neurotransmitter release in the mammalian CNS by an action at a novel GABA receptor. Nature 283:92-94.

Carpenter RHS, Blakemore C (1973) Interactions between orientations in human vision. Exp Brain Res 18:287-303.

Curtis DR, Felix D (1971) The effect of bicuculline upon synaptic inhibition in the cerebral and cerebellar cortices of the cat. Brain Res 34:301-321.
Daniels JD, Pettigrew JD (1973) Gamma-aminobutyric acid antagonism in visual cortex. Different effects on simple, complex and hypercomplex neurones. Science 182:81-82.

Daniels JD, Pettigrew JD (1975) A study of inhibitory antagonism in cat visual cortex. Brain Res 93:41-62.

DeBruyn EJ, Bonds AB (1986) Contrast adaptation in cat visual cortex is not mediated by GABA. Brain Res 383:339-342.

Dutar P, Nicholl RA (1988) A physiological role for GABA-B receptors in the central nervous system. Nature 332:156-158.

Ferster D (1986) Orientation selectivity of synaptic polentials in neurons of cat primary visual cortex. J Neurosci 6:1284-1301

Hirsch JC, Burnod Y (1987) A synaptically evoked late hyperpolarization in the rat dorsolateral geniculate neurons in vitro. Neuroscience 23:457-468.

Kerr DIB, Ong J, Prager RH, Gynther BD, Curtis DR (1987) Phaclofen: a peripheral and central baclofen antagonist. Brain Res 405:150154.

Kerr DIB, Ong J, Johnston GAR, Abbenante J, Prager RH (1988) 2-Hydroxy-saclofen: an improved antagonist at central and peripheral $\mathrm{GABA}_{\mathrm{B}}$ receptors. Neurosci Lett 92:92-96.

Koch C, Poggio T (1985) The synaptic veto mechanism: does it underlie direction and orientation selectivity in the visual cortex? In: Models of the visual cortex (Rose D, Dobson VG, eds), pp 408-419. Chichester: Wiley.

Llinas R, Lopez-Barneo J (1988) Electrophysiology of mammalian tectal neurons in vitro. II. Long-term adaptation. J Neurophysiol 60: 869-878.

Marlin SG, Cynader MS (1987) The spatial spread of adaptation in neurons of cat area 17. Soc Neurosci Abstr 13:1450.

Nelson JI (1985) The cellular basis of perception. In: Models of the visual cortex (Rose D, Dobson VG, eds), pp 108-122. Chichester: Wiley.

Nelson SB (1991a) Temporal interactions in the cat visual system. I. Orientation-selective suppression in the visual cortex. J Neurosci 11 : 344-356.

Nelson SB (1991b) Temporal interactions in the cat visual system. II. Suppressive and facilitatory effects in the lateral geniculate nucleus. J Neurosci 11:357-368.

Newberry NR, Nicholl RA (1984) A bicuculline-resistant inhibitory post-synaptic potential in rat hippocampal pyramidal cells in vitro. J Physiol (Lond) 348:239-254.

Ohzawa I, Sclar G, Freeman RD (1982) Contrast gain control in the cat visual cortex. Nature 298:266-268.

Sherman SM, Koch C (1986) The control of retinogeniculate transmission in the mammalian lateral geniculate nucleus. Exp Brain Res 63:1-20.

Sillito AM (1975a) The effectiveness of bicuculline as an antagonist of GABA and visually evoked inhibition in the cat's striate cortex. J Physiol (Lond) 250:287-304.

Sillito AM (1975b) The contribution of inhibitory mechanisms to the receptive field properties of neurones in the striate cortex of the cat. J Physiol (Lond) 250:305-329.

Sillito AM (1977) Inhibitory processes underlying the direction specificity of simple, complex and hypercomplex cells in the cat's visual cortex. J Physiol (Lond) 271:699-720.

Sillito AM (1979) Inhibitory processes influencing complex cell orientation selectivity and their modification at high discharge levels. $\mathbf{J}$ Physiol (Lond) 289:33-53.

Sillito AM, Kemp JA, Patel H (1980a) Inhibitory interactions contributing to the ocular dominance of monocularly dominated cells in the normal cat striate cortex. Exp Brain Res 41:1-10.

Sillito AM, Kemp JA, Milson JA, Berardi N (1980b) A re-evaluation of the mechanisms underlying simple cell oricntation selectivity. Brain Res 194:517-520.

Tsumoto T, Eckart W, Creutzfeldt OD (1979) Modification of orientation sensitivity of cat visual cortex neurones by removal of GABA mediated inhibition. Exp Brain Res 34:351-363.

Zucker RS (1989) Short-term synaptic plasticity. Annu Rev Neurosci 12:13-31. 